\title{
Glucagon-like peptide-1 and glucagon-like peptide-1 receptor agonists in the treatment of type 2 diabetes
}

\author{
Seungah Lee, $\mathrm{MS}^{1}$, \\ Dong Yun Lee, $\mathrm{PhD}^{1,2}$
}

${ }^{1}$ Department of Bioengineering, College of Engineering, and BK21 PLUS Future Biopharmaceutical Human Resources Training and Research Team, Hanyang University, Seoul, ${ }^{2}$ Institute of Nano Science \& Technology (INST), Hanyang University, Seoul, Korea
Received: 7 March, 2017

Revised: 30 March, 2017

Accepted: 30 March, 2017

Address for correspondence:

Dong Yun Lee, PhD

Department of Bioengineering, College of Engineering, Hanyang University, 222 Wangsimni-ro, Seongdong-gu, Seoul 04763, Korea Tel: $+82-2-2220-2348$

Fax: +82-2-2220-4741

E-mail: dongyunlee@hanyang.ac.kr http://orcid.org/0000-0001-76910447
The prevalence of type 2 diabetes (T2D) is increasing worldwide. Patients with T2D suffer from various diabetes-related complications. Since there are many patients with T2D that cannot be controlled by previously developed drugs, it has been necessary to develop new drugs, one of which is a glucagon-like peptide-1 (GLP-1) based therapy. GLP-1 has been shown to ameliorate diabetes-related conditions by augmenting pancreatic $\beta$-cell insulin secretion and having the low risk of causing hypoglycemia. Because of a very short half-life of GLP-1, many researches have been focused on the development of GLP-1 receptor (GLP-1R) agonists with long half-lives such as exenatide and dulaglutide. Now GLP-1R agonists have a variety of dosing-cycle forms to meet the needs of various patients. In this article, we review the physiological features of GLP-1, the effects of GLP-1 on T2D, the features of several GLP-1R agonists, and the therapeutic effect on T2D.

Keywords: Type 2 diabetes, Glucagon-like peptide-1, Glucagon-like peptide-1 receptor, GLP-1R agonist, GLP-1R agonist clinical trials

\section{Introduction}

A total of 387 million people worldwide have been diagnosed with diabetes, of which approximately 95\% have type 2 diabetes (T2D). Patients with T2D suffer from a number of diabetes-related complications such as cardiovascular disease, neuropathy, nephropathy, and other organ disturbances ${ }^{1)}$. Although the American Diabetes Association recommends metformin treatment as a first-line therapy, metformin treatment alone is insufficient to achieve target blood glucose level in most patients ${ }^{1)}$. Currently, diabetes medications are recommended on a patient-specific basis by considering adverse drug reactions ${ }^{2,3)}$. Several classes of therapy can be used as add-on medications. Based on these findings, many scientists and physicians have developed alternative medications. Among them, glucagon-like peptide-1 (GLP-1) receptor agonists are innovative treatments for T2D. These agonists are beneficial for blood glucose control, pancreatic $\beta$-cell function, and other diabetes-related conditions ${ }^{4-6)}$. Recently the frequency of GLP-1 receptor (GLP-1R) agonist based therapy has been increased, particularly in the United States, Europe, and several other nations. Since GLP-1R agonists differ with respect to clinical efficacy, tolerability, administration requirements, and dosing frequency, each medication potentially provides unique advantages and disadvantages ${ }^{1)}$. The purpose of this article is to summarize current information regarding U.S. Food and Drug Administration (FDA)-approved GLP-1 receptor agonists, with a particular focus on efficacy and clinical studies. Finally, we discuss the potential benefits of these agonists in the treatment of T2D.

\section{Glucagon-like peptide-1}

GLP-1 is the transcription product of a pro-glucagon gene. Absorbed nutrients in the small 
intestine induce GLP-1 secretion from L cells in the intestinal ileum. GLP-1 exerts several effects that are relevant to the treatment of diabetes mellitus. First, GLP- 1 increases glucose transporter 2 expression in pancreatic $\beta$ cells $^{7}$; this molecule plays a role in glucose movement across the cell membrane. Second, GLP- 1 induces pancreatic $\beta$ cells to secret insulin in response to increased glucose contents, while also restricting glucagon release from pancreatic $\alpha$ cells $^{8}$. Third, GLP-1 reduces the secretion of proinflammatory cytokines such as interleukin- 6 , tumor necrosis factor- $\alpha$, and interferon $-c^{9-11)}$. Therefore, GLP- 1 restores pancreatic $\beta$-cell mass and insulin sensitivity. The action of GLP- 1 on the proliferation of $\beta$ cell and antiapoptosis is observed in the experimental animal model, but still not confirmed in the clinical cases ${ }^{12)}$. Finally, the postprandial GLP-1 response is decreased in T2D. This impairment alone could contribute to the pathogenesis of diabetes. However, although GLP-1 secretion is reduced in T2 $\mathrm{D}^{13)}$, patients with T2D who receive GLP-1 infusions exhibit increased insulin release and improved glucose tolerance ${ }^{14)}$. These properties of GLP-1 make it an interesting potential therapeutic agent for T2D.

\section{Structural features of GLP-1 and the GLP-1R}

GLP-1 is a member of the glucagon peptide family and is derived from the preproglucagon gene expression located on chromosome 17. Proprotein convertase (PC) is an important enzyme that activates the product of the pro-glucagon gene by cleaving a peptide at the C-terminal domain, thereby enabling the biological activity of this peptide. Specifically, prohormone convertase $1 / 3$ (PC1/3) generates GLP-1 in intestinal L cells. The GLP-1 peptide is composed of 30 amino acids and undergoes amination of the $\mathrm{C}$-terminal domain. This amination on His7 is required for the enzymatic activities of GLP-1, such as its insulinotropic and glucagon-inhibiting activities. Also, amination extends the survival time of GLP- ${ }^{15,16)}$. GLP- 1 exists in 2 forms, the GLP-1 (7-36) amide form (which accounts for $80 \%$ of all circulating GLP-1) and the GLP-1 (7-37) form, which harbors an additional Gly residue (Gly37) compared to the GLP1 (7-36) amide form ${ }^{17}$. These 2 forms result from tissue-specific differences in posttranslational processing of the preproglucagon gene product. Generally, the GLP-1 (736) amide form is secreted in pancreatic tissue, while GLP-1 (7-37) is secreted in the hypothalamus and intestinal ileum ${ }^{18)}$. The central domain of GLP-1 has an alpha-helical structure, while the $\mathrm{N}$-terminal domain forms a coil structure. Also, the hydrophobic amino acids Phe6 and Val10 and the short chain polar amino acid Thr7 form a helix $\mathrm{N}$ terminus-capping motif through hydrogen bonding and hydrophobic interaction. This capping motif introduces a specific local fold that facilitates receptor activation for peptide-receptor binding ${ }^{19)}$.

GLP-1 mediates its physiological effects by interacting with members of the guanine nucleotide binding protein (G-protein) coupled receptor family ${ }^{20)}$. The GLP-1R is composed of 463 amino acids and has eight hydrophobic domains. GLP- 1 and GLP-1R have important affinity domains determined by ligand selectivity ${ }^{21)}$. Extracellular N-terminal hydrophobic domains, tryptophan residues ${ }^{22)}$, alanine residues ${ }^{23)}$, and cysteine residues $^{24)}$ are critical for the interaction between GLP1 and GLP-1R. In particular, His7 (in the N-terminus of GLP1) has a free alpha-amino group and an imidazole side chain that are important for the GLP-1R/GLP-1 interaction ${ }^{18)}$. In addition, denaturation, isolation, and elimination of the GLP1R N-terminal domain result in loss of affinity for the peptide ${ }^{25}$. Furthermore, residues Tyr 149, Met204, and Tyr205 are required for the biological activity of GLP-1; GLP-1 exerts this activity through the cAMP-dependent pathway ${ }^{26-28)}$.

\section{Physiological properties of GLP-1}

The glucose-dependent insulinotropic reaction is decreased or absent in patients with $\mathrm{T} 2 \mathrm{D}^{29)}$. Pharmacological applications for GLP-1 in patients with T2D have been intensely investigated. When only blood glucose level is highly maintained, GLP1 increases insulin secretion from pancreatic $\beta$-cells while suppressing glucagon secretion from pancreatic $a$ cells ${ }^{4,30)}$. In addition, GLP- 1 controls pancreatic $\beta$ cell proliferation and apoptosis $^{31)}$. Furthermore, GLP-1 controls gastric emptying, motility, colonic transit time, satiety action, energy expenditure, and thermogenesis ${ }^{32-34)}$. Cumulatively, these studies have

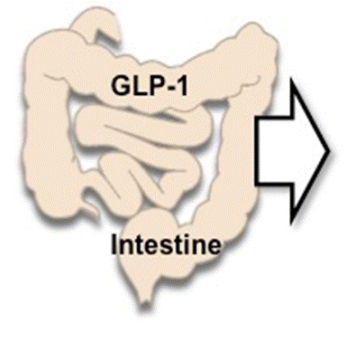

\begin{tabular}{|c|c|}
\hline $\begin{array}{l}\text { Stomach } \\
\text { - } \quad \text { Gastric emptying } \downarrow \\
\text { - } \quad \text { Gastric motility } \downarrow\end{array}$ & $\begin{array}{l}\text { Brain } \\
\text { - } \quad \text { Food uptake } \downarrow \\
\text { - } \quad \text { Body weight } \downarrow\end{array}$ \\
\hline $\begin{array}{l}\text { Colon } \\
\text { - Food transit time } \downarrow\end{array}$ & \multirow{2}{*}{$\begin{array}{ll}\text { Pancreas } \\
\text { - } & \text { Insulin biosynthesis } \uparrow \\
\text { - } & \text { Glucagon secretion } \downarrow \\
\text { - } & \beta \text {-cell apoptosis } \downarrow \\
\text { - } & \beta \text {-cell survival } \uparrow \\
\text { - } & \text { Glucose transporter gene } \uparrow\end{array}$} \\
\hline $\begin{array}{l}\text { Adipose tissue } \\
\text { - } \quad \text { Thermogenesis of BAT } \uparrow \\
\text { - } \quad \text { Browning of white adipose tissue } \uparrow \\
\text { - } \quad \text { Energy expenditure } \uparrow\end{array}$ & \\
\hline
\end{tabular}

Fig. 1. Physiological effect of glucagon like peptide-1 (GLP-1) in peripheral tissues. Interaction between GLP-1 and GLP-1 receptor cause majority of the effect of GLP-1. BAT, brown adipose tissue. 
indicated that GLP-1 is one of potential new drugs for patients with T2D (Fig. 1).

\section{1) Intestine}

GLP-1 affects various gastrointestinal functions such as gastric emptying, motility, and colonic transit time ${ }^{32}$. Interactions between brain and GLP-1 are associated with the inhibition of gastric emptying via the nonadrenergic and noncholinergic pathways $^{32)}$. GLP-1R is highly expressed in myenteric neurons and submucosal neurons of the duodenum and proximal colon $^{35)}$. When GLP-1R is activated in enteric neurons, GLP-1 mediates changes in gastrointestinal function. In addition, GLP1 stimulates innervation to the intestinal circular muscle layer by cholinergic neuron reactions. These reactions are associated with peristalsis because intestinal circular muscle layer contraction is dominant in this process ${ }^{36}$. In addition, GLP- 1 extends colonic transit time by central neuronal actions ${ }^{37,38)}$ and acts on the dorsal motor nucleus of the vagus nerve to mediate changes in parasympathetic neural input. This reaction enhances cholinergic stimulation and affects colon motor contraction, thereby influencing colonic transit time ${ }^{39,40)}$.

Central nervous GLP-1 is important for controlling the satiety actions of central and peripheral nerves. In enteric or vagal neurons, GLP-1 activates brain circuits that affect food intake by inducing c-Fos expression in the hypothalamus paraventricular nucleus (PVN). In addition, leptin receptors are highly expressed in the medial nucleus tractus solitaries (NTS), which is the main site of GLP-1 action ${ }^{41,42)}$. These findings suggest that central endogenous GLP-1 produced in the NTS might act on GLP-1R in the same nuclei, and that these feedback loops are associated with satiety roles.

\section{2) Brain}

In the brain, GLP-1 is produced by noncatecholaminergic neurons of the nucleus of solitary tract (NTS $)^{43)}$. These neuron stretches throughout areas in the hindbrain and hypothalamus such as the PVN, the dorsal medial nucleus of the hypothalamus, and the arcuate nucleus (ARC). Moreover, gutderived GLP-1 interacts with the brain by GLP-1R expressed in innervating fiber neurons ${ }^{44)}$, where the blood-brain barrier has enhanced permeability.

In one study that aimed to identify the specific neuronal site affected by GLP-1R agonist interaction with GLP-1R, the gene encoding GLP-1R in the central nervous system (CNS) or peripheral nervous system was deleted ${ }^{45}$. That study found that the loss of GLP-1R in the CNS did not affect the regulation of food uptake or body weight, while peripheral nervous system GLP-1R reduction was associated with decreased food uptake and weight loss. This result demonstrates that the peripheral nervous system is essential for complete anorectic response and weight loss effects. Another study was conducted to identify the peripheral neuronal mechanism associated with the effects of GLP-1R on food uptake and weight $\operatorname{loss}^{46}$. In that study, GLP$1 \mathrm{R}$ antagonist was injected into nerves in specific regions or into nuclei in an ex vivo electrophysiological study. Also, fluorescent- labeled GLP-1R antagonists were peripherally administered in a rat model. That study found that the ARC was responsible for controlling appetite and weight loss. Specifically, neuropeptide Y/agouti-related protein (NPY/AgRP) neurons control appetite by the orexigenic effect ${ }^{47}$, and pro-opiomelanocortin/cocaineand amphetamine-regulated transcript (POMC/CART) neurons are sensitive to peripheral hormones such as insulin and leptin by anorexigenic effects ${ }^{48)}$.

Aside from these examples, no uptake of peripherally administrated GLP-1R agonist was found in the NTS. In addition, a GLP-1R agonist was shown to act indirectly through gammaAminobutyric acid neurons to inhibit NPY/AgRP neurons in the $\mathrm{ARC}^{44)}$.

\section{3) Pancreas}

GLP-1R is highly expressed on the pancreatic $\beta$-cell membrane ${ }^{49,50)}$. In the presence of high concentrations of glucose, GLP-1 interacts with GLP-1R, resulting in cyclin AMP (cAMP) formation $^{14)}$. The subsequent increase in cAMP leads to the activation of cAMP-regulated guanine nucleotide exchange factor 2 (cAMP-GEFII or Epac2) and protein kinase A (PKA). Epac2 and PKA modulate ion channel activity, specifically by closing $\beta$-cell ATP sensitive potassium channels. As a result, the membrane potential changes, and the pancreatic $\beta$ cells are sensitized to glucose. In addition, Epac-2 is associated with a critical step in signaling pathways such as those containing Ras superfamily guanine nucleotide exchange factor binding proteins. Epac-2 is also associated with $\mathrm{Ca}^{2+}$ release from the endoplasmic reticulum, resulting in exocytosis of insulin-containing vesicles ${ }^{49)}$. Also, PKA is associated with phosphorylation reactions important for insulin secretion from pancreatic $\beta$ cells ${ }^{51,52)}$. GLP-1 also regulates the expression of specific genes in pancreatic $\beta$ cells ${ }^{49,50,53)}$. First, increased intracellular $\mathrm{Ca}^{2+}$ concentration affects the level of insulin gene transcription. As a result, intracellular insulin contents are increased, thereby elevating the insulin contents of $\beta$ cells. Secondly, GLP-1 activates pancreatic duodenal homeobox-1 (PDX-1), which is associated with insulin gene transcription. Additionally, PDX-1 is a critical factor for promoting $\beta$-cell proliferation, differentiation, and survival. Moreover, GLP1 promotes glucose-dependent insulin secretion when the intracellular insulin contents of pancreatic $\beta$-cell increase $e^{54)}$. Furthermore, GLP-1 increases the expression of glucose transporter genes and glucokinase, which are associated with glucose transport and metabolism ${ }^{49,50)}$. GLP-1 also prevents pancreatic $\beta$-cell apoptosis ${ }^{54)}$ by controlling the expression of bcl-2 (antiapoptotic protein) and caspase-3 (pro-apoptotic protein). In in vitro studies of the effects of GLP- 1 on pancreatic $\beta$ cells, GLP-1-treated human islets showed increased level of bcl-2 protein and decreased level of caspase- 3 protein ${ }^{54}$. Also, GLP-1-treated islets had more normal morphology compared to untreated islets.

Recent studies have demonstrated that GLP-1 also affects pancreatic $\alpha$ cells by improving abnormalities in $\alpha$-cell glucose sensing. These studies have found that, when given before a 
meal, GLP-1 decreases prandial glucose release and inhibits inappropriate meal-induced glucagon release. Another study compared the effects of GLP- 1 on patients with T2D versus nondiabetic subjects and found that glucose-infused patients with diabetes showed transient increase in glucagon level and failed to suppress hyperglycemia conditions. Moreover, subsequent GLP-1 infusion during hyperglycemia led to decreased plasma glucagon level in patients with T2D compared to those of nondiabetic subjects ${ }^{55}$. In a long-term study of GLP1-based therapy in T2D, continuous infusion of GLP-1 tended to lower glucagon level and to substantially reduce blood glucose level $^{56)}$.

\section{4) Adipose tissue}

The relationships between brown adipose tissue (BAT) thermogenesis and white adipose tissue (WAT) browning with GLP-1 action are largely unknown, but recent studies have attempted to answer this difficult question. For instance, GLP1 was recently found to regulate BAT thermogenesis without causing any diet changes ${ }^{57}$. Also, many genes associated with the thermogenic program are highly expressed in the brain, such as uncoupling protein-1 (UCP-1) and peroxisome proliferator activated receptor gamma co-activator-1 alpha ${ }^{57}$. In contrast, a GLP-1 receptor knock-out mouse did not show any change in BAT thermogenesis or expression of genes involved in the thermogenic program. Also, central injection of GLP-1R agonists resulted in electrophysiological activity of sympathetic fibers. These results indicate that interaction between the brain and BAT is associated with the sympathetic nervous system. Furthermore, central injection of GLP-1R agonists resulted in WAT browning. It is well known that many neurons in the CNS express GLP-1R, especially ventromedial nucleus (VMH) neurons in the hypothalamic nuclei, an area critical for energy balance ${ }^{58,59)}$. VMH neurons modulate sympathetic nervous systems such as the raphe pallidus and inferior olive systems. These 2 sympathetic nervous systems are associated with regulation of BAT thermogenesis ${ }^{60,61)}$. Furthermore, a VMH knockout mouse showed lower energy expenditure and UCP1 expression in $\mathrm{BAT}^{62,63)}$. In addition, gene modulation studies have demonstrated the effect of VMH in BAT thermoregulation. Specifically, in the VMH knockout mouse, steroidogenic factor- 1 neurons showed lower energy expenditure and decreased amount of UCP-1 in the BAT ${ }^{(2,63)}$ Furthermore, AMPactivated protein kinase in the VMH sympathetically regulates thyroid hormone and estradiol, thereby affecting thermogenesis by $\mathrm{BAT}^{64,65)}$.

A few studies have demonstrated the central control of WAT browning. In one study, brain SIRT-1 (NAD-dependent deacetylase sirtuin-1) was determined to play a critical role in WAT browning. Moreover, SIRT-1-knockout POMC neurons were shown to exhibit reduced sympathetic nerve activity, UCP1 expression, and brown fat-like activity in perigonadal WAT ${ }^{66)}$. Another study also suggested that AgRP neurons within the ARC inhibit the WAT browning effect ${ }^{34)}$.

\section{Limitations of GLP-1 in the treatment of T2D}

Native GLP-1 has a very short half-life (about 2 minutes) because of rapid degradation by the endogenous enzymes dipeptidyl-peptidase-IV (DPP-4) ${ }^{67)}$ and neutral endopeptidase $(\mathrm{NEP})^{68}$. DPP-4 is an exopeptidase that is highly concentrated in hepatocytes, intestinal brush-border membranes, the kidney, the capillary endothelium, and plasma ${ }^{69}$. This enzyme cleaves peptide bonds and ultimately releases a single amino acid or dipeptide from the native peptide chain. Native GLP-1 is cleaved by DDP- 4 directly after 7 His and $8 \mathrm{Ala}, 2 \mathrm{~N}$-terminal amino acids. The cleaved fragment (9-36) does not exert insulinotropic effects $^{70)}$. Also, native GLP-1 is degraded by neutral endopeptidase 24.11 (NEP 24.11), also known as neprilysin ${ }^{68)}$. This enzyme is a zinc-dependent metallopeptidase that is expressed in many different tissues, with especially high expression level in the kidney. NEP 24.11 cleaves a hydrophobic residue or the $\mathrm{N}$-terminal side of aromatic residues from native peptides. The modified GLP-1 fragment undergoes rapid renal clearance ${ }^{71)}$. Therefore, it is necessary to develop modified versions of GLP-1 or to synthesize GLP-1R agonists to achieve better bioavailability and clinical efficacy in the treatment of patients with T2D.

\section{Pharmacokinetics of FDA-approved GLP-1R agonists}

Synthetic GLP-1R agonists are resistant to degradation by DPP-4 and consequently exhibit extended bioavailability, thereby improving their clinical efficacy. These agonists bind to

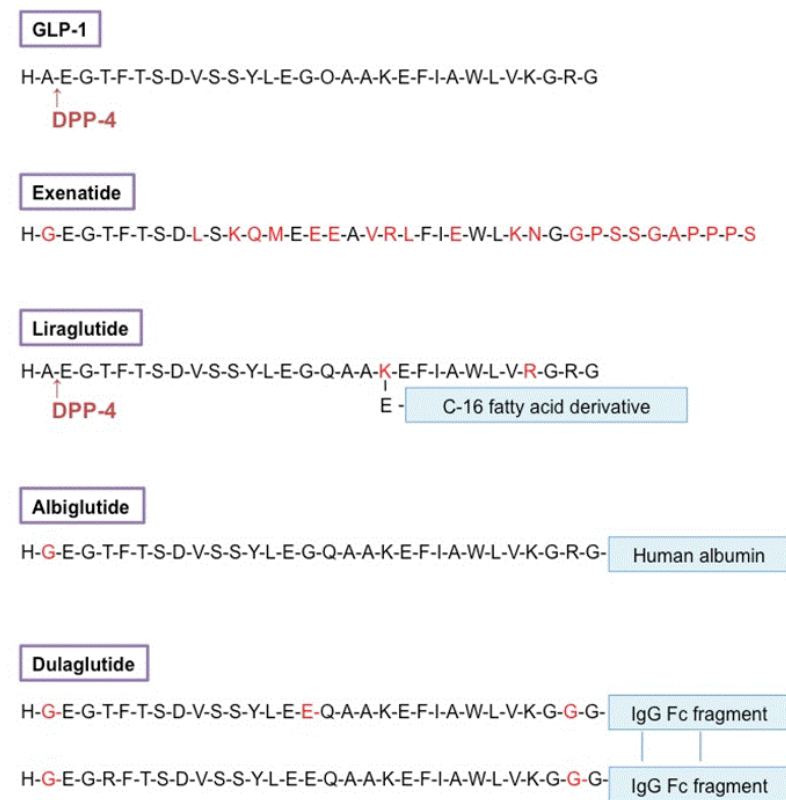

Fig. 2. Amino acid sequence of glucagon like peptide-1 (GLP-1) and GLP-1 receptor agonists, exenatide, liraglutide, albiglutide and dulaglutide. Modified amino acids are highlighted in red. 
GLP-1R and stimulate its pharmacological effects, increasing glucose-dependent insulin release from pancreatic $\beta$ cells, suppressing the release of glucagon from pancreatic a cells, delaying the rate of gastric emptying, and slowing the glucose absorption rate. Several FDA-approved GLP-1R agonists are available for use in the United States and the European Union (Fig. 2). Since the molecular structure, pharmacokinetics, efficacy, administration requirements, and tolerability may differ between GLP-1R agonists, each agonist offers specific advantages and disadvantages. Consequently, each agonist should be assessed independently, and therapeutic regimens should be customized to individual patients.

\section{Exenatide}

The first GLP-1R agonist to be approved was Exenatide (marketed as Byetta), which was approved by the FDA in 2005. Exenatide is a synthetic form of excendin-4, which is a hormone found in gila monster saliva that is composed of 39 amino acid peptides and shares 53\% sequence homology with GLP-1 ${ }^{72)}$, making it a potent GLP-1R agonist. Exenatide is also resistant to degradation by DPP-4 because it has Gly8 in the place of Ala8, the residue on which DPP- 4 acts. Furthermore, there are no target sites for NEP 24.11 $1^{73)}$ in exenatide, the longer C-terminus of which may be responsible for its prolonged half-life (about 2-4 hours in humans ${ }^{74)}$ ). Like GLP-1, exenatide binds to GLP$1 \mathrm{R}$ and has several antihyperglycemic effects, such as increasing glucose-dependent insulin release and decreasing glucagon level $^{75,76)}$.

Exenatide has been used as a monotherapy or in combination with insulin or oral agents. Because exenatide restores the normal first-phase insulin release that is lost in people with diabetes, it should be injected before meals to successfully suppress hepatic glucose production ${ }^{1)}$. Exenatide must be injected subcutaneously (abdomen, thigh, or upper arm) twice daily prior to eating meals; to minimize the risk of hypoglycemia, injections should be administrated at intervals of at least 6 hours. At the beginning of treatment, patients should be injected with 5- $\mu$ g doses to increase drug tolerability. Since exenatide has dose-dependent effects ${ }^{77)}$, after 1 month of drug administration, patients should be injected with $10-\mu \mathrm{g}$ doses ${ }^{1)}$. If the patients become noncompliant with the $10-\mu \mathrm{g}$ doses due to side effects such as nausea or vomiting, a 5- $\mu \mathrm{g}$ dose has also been shown to lower overall glycosylated hemoglobin (HbAlc) concentration $^{1,77)}$.

Another long-acting exenatide, Bydureon, is administrated once weekly. This therapeutic was introduced in the United States in 2012. Bydureon has the same pharmacological compound, exenatide, and is given twice daily. Specifically, Bydureon consists of a poly-microsphere drug carrier that releases exenatide into the blood for 10 days, resulting in sustained drug release and longer lasting effects. Bydureon is administered once weekly in 2-mg doses through the subcutaneous route ${ }^{1)}$.

\section{Exenatide in clinical trials}

The efficacy of twice-daily exenatide treatment of patients with T2D has been evaluated in multiple phase 3 clinical studies. One such study was entitled "AC2993: Diabetes Management for Improving Glucose Outcomes (AMIGO)." The AMIGO-1 study was a 30 -week study that assessed the clinical efficacy of twice-daily exenatide to ameliorate glycemic control in patients with T2D who were already receiving metformin therapy. Patients already receiving $1,500 \mathrm{mg}$ of once-daily metformin were randomized to receive placebo, twice-daily exenatide ( 5 $\mu \mathrm{g})$ for the entire study period, or twice-daily exenatide $(5 \mu \mathrm{g})$ for the first 4 weeks, after which the dose was changed to $10 \mu \mathrm{g}$ twice daily. At the termination of the study, patients who were treated with $10-\mu$ g twice-daily exenatide exhibited reduction of $\mathrm{HbA} 1 \mathrm{c}$ level by about $0.78 \%$, while the 5 - $\mu$ g twice-daily groups achieved approximately $0.4 \%$ reduction. These reductions were statistically significant compared with placebo values $(P<0.002)$. Also, participants who were given either dose of exenatide (5 or $10 \mu \mathrm{g}$ ) experienced significant dose-dependent weight loss. However, adverse symptoms such as nausea, vomiting, and hypoglycemia were frequently observed with exenatide treatment. These results indicate that exenatide treatment for T2D can yield an additive effect in patients unable to achieve appropriate glycemic control with metformin therapy ${ }^{77)}$.

Twice-daily exenatide was demonstrated to yield superior glycemic control compared with a dipeptidyl peptidase inhibitor (sitagliptin ${ }^{78)}$. In one clinical trial, participants already taking metformin received a $100-\mu \mathrm{g}$ dose of sitagliptin daily for 2 weeks or a 5- $\mu$ g dose of exenatide twice a day for 1 week. The latter dose was titrated to $10 \mu \mathrm{g}$ of exenatide twice daily for 1 week. At the study's conclusion, participants who received exenatide treatment exhibited significantly reduced postprandial glucose level. Furthermore, the exenatide treatment group showed significantly increased insulin secretion and decreased postprandial glucagon secretion. Although the duration of this trial was relatively short, it demonstrated that GLP-1R agonists enable superior glycemic control compared to DPP-4 inhibitors ${ }^{78)}$.

The clinical efficacy of once-weekly exenatide was examined in multiple phase 3 studies, including the DURATION program (Diabetes Therapy Utilization: Researching changes in A1C, Weight and Other Factors Through Intervention with Exenatide Once Weekly). The DURATION trials estimated the efficacy and safety of a 2-mg dose of exenatide once weekly in patients with $\mathrm{T} 2 \mathrm{D}^{5)}$ and compared them to those of several another treatments such as twice-daily exenatide, insulin glargine, liraglutide, and other medications ${ }^{1,5,79,80)}$. In one clinical trial, a once-weekly 2-mg dose of exenatide was compared with a twice-daily $10-\mu \mathrm{g}$ dose of exenatide. The duration of this trial was 30 weeks, and participants were given metformin as a background treatment. At the termination of the study, participants exhibited significantly reduced $\mathrm{HbAlc}$ level (approximately 1.9\% compared with 1.5\% reduction with twice- 
daily exenatide $[P=0.0023])$. Moreover, $77 \%$ of participants achieved a target $\mathrm{HbAlc}$ level when treated with once-weekly exenatide compared with $61 \%$ of twice-daily exenatide group $(P=0.0039)$. Furthermore, the once-weekly exenatide group experienced significantly reduced fasting and postprandial glucose level. Since the poly-microsphere form of once-weekly exenatide results in more sustained drug-release compared with the daytime drug-release of twice-daily exenatide ${ }^{1)}$, the fasting glucose level was more highly decreased in the once-weekly exenatide group and the postprandial glucose level was greatly reduced with the twice-daily form ${ }^{5}$. Regarding adverse effects, more participants receiving once-weekly exenatide experienced injection site pruritus, while treatment-related nausea and vomiting were more frequent in the twice-daily exenatide group. Cumulatively, the data from this trial indicate that once-weekly exenatide is superior for achieving target $\mathrm{HbAlc} \mathrm{level} \mathrm{and} \mathrm{blood}$ glucose level without increasing the rate of hypoglycemia ${ }^{5)}$.

In the DURATION-6 trial, the clinical efficacy of once-weekly exenatide was evaluated and compared to that of liraglutide, an FDA-approved GLP-1R agonist ${ }^{79}$. While participants continued background medications such as metformin, they were randomized to receive a $2-\mathrm{mg}$ dose of exenatide once weekly or a $1.8-\mathrm{mg}$ dose of daily liraglutide. At the conclusion of the study, the exenatide-treated group exhibited a significant reduction of $\mathrm{HbAlc}$ (about 1.28\%), while the liraglutide-treated group showed a $1.48 \%$ reduction $(P=0.02)^{79}$. All participants experienced treatment-dependent weight loss; liraglutidetreated patients exhibited greater weight $\operatorname{loss}^{79)}$, although patients receiving once-weekly exenatide maintained this weight loss for a longer duration ${ }^{1)}$. Also, liraglutide-treated patients experienced a significant reduction in fasting blood glucose level compared with once-weekly exenatide-treated patients $(P=0.02)$. However, some of the liraglutide-treated patients displayed adverse symptoms such as nausea, and more patients quit liraglutide therapy because of severe adverse effects ${ }^{79)}$.

In the DURATION-3 trial, the clinical efficacy of onceweekly exenatide was estimated and compared to that of insulin glargine for 26 weeks. Participants were randomized to receive a 2-mg dose of weekly exenatide or an initial dose of 10 units of daily insulin glargine with background metformin therapy, with or without sulfonylurea. If the participant experienced treatment-dependent hypoglycemia, the sulfonylurea dose was reduced. At the conclusion of the study, the once-weekly exenatide-treated group exhibited significantly reduced HbAlc level (about 1.5\%) $(P=0.017)$ compared with the insulin glargine-treated group $(1.3 \%)^{80)}$. Furthermore, because of the effects of the GLP-1R agonists on caloric intake, satiety, and postprandial glucose concentrations ${ }^{81,82)}$, once-weekly exenatide-treated patients experienced greater reductions in postprandial glucose concentration ${ }^{80}$. Also, exenatide-treated patients experienced greater weight loss compared with the treatment-dependent weight gain of insulin therapy (about 1.4 $\mathrm{kg}$ ). With respect to adverse symptoms, once-weekly exenatidetreated patients experienced higher rates of adverse effects such as nausea and vomiting. However, hypoglycemia occurred more frequently with insulin glargine treatment, especially with background sulfonylurea therapy ${ }^{800}$.

The trials above indicate that once-weekly exenatide should be given to patients with other medications for a few weeks to ensure that optimum glycemic control is achieved, since the steady state concentrations of once-weekly exenatide are reached within 1 week $^{6)}$.

\section{Liraglutide}

Liraglutide (Victoza) was introduced in the United States in 2010 as a second GLP-1R agonist. This protein has 97\% sequence homology with native GLP- $1^{1)}$ and exhibits a prolonged half-life of 13 hours. The long half-life is achieved by peptide acylation with a fatty acid at Lys 26 via a glutamoyl spacer, forming a lipophilic micelle-like structure ${ }^{83}$. Acylated liraglutide adheres to albumin and self-associates after subcutaneous injection. This phenomenon allows the slow release from albumin, delayed degradation, and reduced renal clearance of liraglutide compared to GLP- ${ }^{84)}$. Liraglutide exerts a number of effects similar to those exerted by GLP-1. For instance, liraglutide attenuates $\beta$-cell apoptosis and stimulates glucose-dependent insulin secretion from pancreatic $\beta$ cells. Furthermore, compared to exenatide, liraglutide is more efficient in decreasing $\mathrm{HbAlc}$ because of its longer half-life ${ }^{6)}$.

Liraglutide, which is administered using prefilled pens, has been used as monotherapy as an adjunct to exercise and diet or in combination with basal insulin and oral agents in patients with T2D. Liraglutide is not considered a first line therapy. Initially, liraglutide should be given to patients at a dose of 0.6 mg once daily for 1 week to increase drug tolerability. The dose should then be adjusted to $1.2 \mathrm{mg}$ per day. If the glycemic goals are not achieved, the dose can be increased to $1.8 \mathrm{mg}$ per day ${ }^{83)}$.

\section{Liraglutide in clinical trials}

The clinical efficacy of once-daily liraglutide in patients with T2D was demonstrated in a study series entitled 'LEAD (Liraglutide Effect and Action in Diabetes)'. In the LEAD6 clinical study, which lasted for 26 weeks, the efficacy of liraglutide with background metformin and/or sulfonylurea therapy was compared with that of twice-daily exenatide ${ }^{6}$. Participants with $\mathrm{HbAlc}$ level ranging from $7 \%-11 \%$ were randomized to receive daily liraglutide $(1.8 \mathrm{mg})$ after a titration period of once-weekly liraglutide $(0.6 \mathrm{mg})$, once-weekly $(1.2$ $\mathrm{mg}$ ) for 2 weeks, or $5 \mu \mathrm{g}$ of exenatide twice daily for 4 weeks. The latter dose was titrated to $10 \mu \mathrm{g}$ twice daily. At the conclusion of this trial, the liraglutide-treated group exhibited a significant reduction in $\mathrm{HbAlc}$ level by about $1.12 \%$ compared to the exenatide group, which had $0.79 \%$ reduction. Also, $54 \%$ of the participants in the liraglutide therapy group achieved the target $\mathrm{HbAlc}$ level, compared to more than $43 \%$ of the participants in the exenatide-treated group. With respect to reducing blood glucose level, liraglutide was superior for the fasting state, while 
exenatide was better for the postprandial state $(P<0.0001)$. Both groups showed similar weight loss (approximately $3 \mathrm{~kg}$ ). Adverse effects such as nausea occurred in both groups at similar rates. However, the liraglutide-treated group showed rapid recovery from symptoms within 6 weeks, while the exenatide-treated group required 22 weeks ${ }^{6}$.

In the LEAD-5 trial, liraglutide was compared with insulin glargine in patients with background metformin and/or sulfonylurea therapies. Participants were randomized to receive once-daily liraglutide $(1.8 \mathrm{mg})$ after a 2 -week titration time or insulin glargine ${ }^{85)}$. At the conclusion of the 26-week study, the liraglutide-treated group exhibited significantly reduced $\mathrm{HbA1c}$ level (approximately 1.33\% reduction), while the insulin-treated group exhibited a $1.01 \%$ reduction in $\mathrm{HbAlc}$ level. Also, the liraglutide-treated group experienced weight loss and mild to moderate gastrointestinal symptoms such as mainly nausea (14\%), diarrhea and vomiting, while the insulin-therapy group gained weight. The rates of hypoglycemia were similar between the 2 groups. This study demonstrated that liraglutide has clinical efficacy for reducing HbAlc level and body weight in patients with T2D, without causing severe side effects ${ }^{85}$.

\section{Albiglutide (Tanzeum)}

In 2014, the FDA approved albiglutide (Tanzeum), a GLP$1 \mathrm{R}$ agonist, as an adjunct to exercise and diet for improving glycemic control in T2 $\mathrm{D}^{86)}$. Albiglutide increases glucosedependent insulin secretion, slows gastric emptying, and decreases food uptake86). Furthermore, albiglutide has a prolonged half-life (about 5 days ${ }^{87)}$ ) due to the replacement of two amino acids (alanines) with glycines, thereby allowing albiglutide to bind albumin in vivo.

Similar to other GLP-1R agonists, albiglutide is not considered a first-line agent ${ }^{1}$. Albiglutide is given as a $30-\mathrm{mg}$ dose once a week by subcutaneous injection (abdomen, upper arm, or thigh) or by pens prefilled with a powder; doses are administered regardless of meal timing. Following initial administration, therapeutic concentrations of albiglutide can be achieved within 5 days. Steady state concentrations are maintained by 28-35 days after the initial injection ${ }^{1,87)}$. For patients who cannot achieve appropriate glycemic control with 30 -mg albiglutide, the dose can be increased to $50 \mathrm{mg}$ once weekly, which has been shown to result in improved glycemic control ${ }^{1)}$.

\section{Albiglutide in clinical trials}

The clinical trials of albiglutide comparing with that of insulin glargine in patients with T2D were conducted in a study series entitled HARMONY. In the HARMONY-2 (efficacy and safety of once-weekly GLP-1 receptor agonist albiglutide) clinical study, patients were randomized to receive either onceweekly albiglutide (30 mg, titrated up to $50 \mathrm{mg}$ if required for glycemic control) or 10 units of insulin glargine once daily. At the end of the treatment period, HbAlc level had decreased (by about $0.66 \%$ ) in the albiglutide group, while that in the insulin glargine group had decreased by $0.81 \%$. This study demonstrates the noninferiority of albiglutide treatment with respect to glycemic control. Furthermore, the insulin-treated group exhibited treatment-related weight gain, while albiglutide confers additional benefits such as weight loss ${ }^{88)}$. In the HARMONY-3 clinical trials (104-week randomized, doubleblind, placebo- and active-controlled trial assessing the efficacy and safety of albiglutide compared with placebo, sitagliptin, and glimepiride in patients with T2D taking metformin), the efficacy of albiglutide was examined in patients with T2D which was not controlled by metformin alone therapy. Participants (average $\mathrm{HbAlc}$ level of $8.3 \%^{89,90)}$ ) were randomized to receive albiglutide or a DPP-4 inhibitor (sitagliptin) based on presence of metformin therapy. In participants who received albiglutide, $\mathrm{HbA1c}$ and fasting blood glucose levels were significantly reduced compared with those in sitagliptin-treated participants. Of particular note, albiglutide is noninferior to insulin glargine and inferior to sitagliptin. In the HARMONY-7 trial (onceweekly albiglutide versus once-daily liraglutide in patients with T2D inadequately controlled on oral drugs) ${ }^{89)}$, participants were randomized to receive either a $30-\mathrm{mg}$ dose of albiglutide once weekly, titrated to a 50-mg dose once weekly after 6 weeks, or a $0.6 \mathrm{mg}$ daily dose of liraglutide, titrated to $1.8 \mathrm{mg}$ after 2 weeks. At the conclusion of the 32 weeks trial, $52 \%$ of the liraglutide-treated participants had reached their $\mathrm{HbAlc}$ level under $7 \%$ while $42 \%$ of albiglutide-treated groups had achieved. Noninferiority of albiglutide could not be demonstrated in head-to-head trials with liraglutide. Also, weight loss and gastrointestinal side effects were not as frequent compared to those in patients receiving liraglutide ${ }^{89,90)}$. However, adverse symptoms such as nausea, vomiting, and hypoglycemia were more frequent with liraglutide therapy. These clinical trials indicate that albiglutide therapy yield better results for patients who experience intolerable adverse symptoms in response to short-acting GLP-1R agents.

\section{Dulaglutide (GLP-1Fc, Trulicity; LY2189265)}

Dulaglutide (Trulicity) received FDA approval in 2014 as a long-acting human GLP-1R agonist and is given as an adjunct to diet and exercise for T2D. Dulaglutide consists of 2 disulfidelinked chains that contain a sequence analogous to GLP-1. Specifically, the sequence is approximately $90 \%$ homologous to that of native GLP-1. These chains are covalently linked to a modified immunoglobulin G4 heavy chain fragment (IgG4-Fc) by a small peptide linker. The modified IgG4-Fc domain of the molecule reduces its immunologic cytotoxicity ${ }^{91)}$ by suppressing Fc receptor affinity potential. Also, this structure optimizes the clinical effects of dulaglutide by protecting it from DPP-4mediated degradation ${ }^{91)}$. Furthermore, the increased molecule size resulting from IgG4-Fc linkage reduces the elimination rate $^{92)}$. Due to these features, dulaglutide has a significantly prolonged half-life of approximately 5 days, making it 
Table 1. Pharmacokietic parameters of glucagon-like peptide 1 (GLP-1) receptor agonists approved by U.S. Food and Drug Administration

\begin{tabular}{|c|c|c|c|c|c|c|c|}
\hline Drug & Half life & Brand name & Dosing frequency & US FDA approved & Cmax & Tmax & Reference \\
\hline GLP-1 & $<2 \mathrm{Mo}$ & - & - & - & - & - & $67,68)$ \\
\hline Exenatide & $2-4 \mathrm{Hr}$ & Byetta & Twice daily & Apr, 28. 2005 & $211 \mathrm{pg} / \mathrm{mL}$ & $1.5 \mathrm{Hr}$ & 97) \\
\hline Extended-release exenatide & $2-4 \mathrm{Hr}$ & Bydureon & Once weekly & Jan, 26, 2012 & $211 \mathrm{pg} / \mathrm{mL}$ & $1.5 \mathrm{Hr}$ & 97) \\
\hline Liraglutide & $13 \mathrm{Hr}$ & Victoza & Once daily & Jan, 25, 2010 & 35 ng/mL & $8-12 \mathrm{Hr}$ & 83) \\
\hline Albiglutide & 5 Days & $\begin{array}{l}\text { Tanzeum (US) } \\
\text { Eperzam (EU) }\end{array}$ & Once weekly & Apr, 15, 2014 & $1.74 \mu \mathrm{g} / \mathrm{mL}$ & 3-5 Days & 98) \\
\hline Dulaglutide & 5 Days & Trulicity & Once weekly & Sep, 18, 2014 & $114 \mathrm{ng} / \mathrm{mL}$ & $48 \mathrm{Hr}$ & 99) \\
\hline
\end{tabular}

appropriate for once-weekly administration.

Dulaglutide is administrated in combination with other drugs, together with exercise and diet, to improve glycemic control. Dulaglutide is administrated once a week as a 0.75 -mg dose by subcutaneous injection at any time, regardless of meal timing ${ }^{92)}$, and the dose can be increased to $1.5 \mathrm{mg}$ per week for additional glycemic control ${ }^{1)}$. Therapeutic concentrations are achieved within 1-3 days and are steadily maintained during 2-4 weeks after weekly drug administration. However, dulaglutide is not recommended for patients with type 1 diabetes or patients whose diabetes is uncontrollable with diet and exercise ${ }^{92)}$.

\section{Dulaglutide in clinical trials}

AWARD (The Assessment of Weekly AdministRation) clinical trials were conducted to determine the efficacy of dulaglutide for achieving glycemic control in T2D and included a variety of phase 3 trials. Dulaglutide was compared to twicedaily exenatide, insulin glargine, metformin, and liraglutide ${ }^{93-96)}$ in combination with background therapy, depending on the trial. In the AWARD-1 trial (Efficacy and Safety of Dulaglutide Added On to Pioglitazone and Metformin Versus Exenatide in T2D in a Randomized Controlled Trial) ${ }^{93)}$, randomized participants were received once-weekly dulaglutide $1.5-\mathrm{mg}$ or exenatide twice daily $(10-\mu \mathrm{g})$ with background therapy of metformin and pioglitazon. Participants receiving a $1.5-\mathrm{mg}$ dose of dulaglutide experienced dose-dependent reduction in HbAlc level by about $1.51 \%$, while patients receiving twicedaily exenatide showed $0.99 \%$ reduction. The 2 groups had similar weight loss, $1.3 \mathrm{~kg}$, and both groups experienced similar incidences of gastrointestinal side effects ${ }^{93)}$. Overall, under the background therapy of metformin and pioglitazone, onceweekly dulaglutide therapy has superior clinical efficacy without any tolerability and side effect than twice-daily exenatide therapy. In the AWARD-2 trial (Efficacy and Safety of Once Weekly Dulaglutide vs. Insulin Glargine in Combination with Metformin and Glimepiride in T2D Patients) ${ }^{94)}, 0.75$ - and 1.5mg doses of once-weekly dulaglutide were compared with a 1.5-mg dose of insulin glargine, titrated to target a fasting blood glucose level around $100 \mathrm{mg} / \mathrm{dL}$, based on metformin treatment. In this study, dulaglutide-treated participants exhibited a $0.9 \%$ reduction in $\mathrm{HbA1c}$ with the $0.75 \mathrm{mg}$ dulaglutide dose, $0.59 \%$ reduction with the $1.5-\mathrm{mg}$ dulaglutide dose, and $0.62 \%$ reduction with insulin glargine. Also, dulaglutide-treated participants experienced dose-dependent weight loss, while the insulin glargine-treated group showed almost $1.28-\mathrm{kg}$ weight gain. These results demonstrate that a 1.5 - $\mathrm{mg}$ dose of dulaglutide is superior to insulin glargine, and that a 0.75 $\mathrm{mg}$ dose of dulaglutide is noninferior to insulin glargine ${ }^{94)}$. In the AWARD-6 trial (once-weekly dulaglutide versus oncedaily liraglutide in metformin-treated patients with T2D $)^{96)}$, participants received a $1.5-\mathrm{mg}$ dose of dulaglutide once weekly or a 1.8-mg dose of liraglutide once daily, with background metformin therapy, for 26 weeks. At the termination of the study, the dulaglutide group and the liraglutide group showed a decrease in $\mathrm{HbAlc}$ levels of $1.42 \%$ and $1.36 \%$, respectively $(P<0.0001)$. The liraglutide group demonstrated significantly higher weight loss compared to the dulaglutide group (3.6 kg vs. $2.9 \mathrm{~kg}, P<0.001)$. Also, no significant differences were observed between the 2 groups with respect to adverse effects. This study showed that once-weekly dulaglutide has noninferiority to once-daily liraglutide in reducing $\mathrm{HbAlc}$ with a similar safety profile $^{96)}$.

\section{Conclusions}

GLP-1R agonist therapies are breakthrough medications for patients with T2D and can help them achieve weight loss, improve $\beta$-cell function, and reduce a risk of causing hypoglycemia. In addition, GLP-1R agonist therapy has a variety of dosing cycles, such as once-daily injections, twice-daily injections, and once-weekly injections, which was summarized in Table 1. GLP-1R agonists have the advantage of being able to choose the appropriate agent according to the patient's various lifestyles. In conclusion, optimally employing GLP-1R agonists, better glycemic control can be enabled.

\section{Conflict of interest}

No potential conflict of interest relevant to this article was reported.

\section{Acknowledgments}

This study was supported by a grant from the National Leading Research Laboratory (NRF-2015R1A2A1A05001832) and a grant from the Basic Science Research Program (NRF- 
2015M3A9E2030125) through the National Research Foundation of Korea (NRF), funded by the Ministry of Science, ICT, \& Future Planning, Korean Government.

\section{References}

1. Prasad-Reddy L, Isaacs D. A clinical review of GLP1 receptor agonists: efficacy and safety in diabetes and beyond. Drugs Context 2015;4:212283.

2. Inzucchi SE, Bergenstal RM, Buse JB, Diamant M, Ferrannini E, Nauck M, et al. Management of hyperglycaemia in type 2 diabetes: a patient-centered approach. Position statement of the American Diabetes Association (ADA) and the European Association for the Study of Diabetes (EASD). Diabetologia 2012;55:1577-96.

3. Garber AJ, Abrahamson MJ, Barzilay JI, Blonde L, Bloomgarden ZT, Bush MA, et al. AACE comprehensive diabetes management algorithm 2013. Endocr Pract 2013;19:327-36.

4. Baggio LL, Drucker DJ. Biology of incretins: GLP-1 and GIP. Gastroenterology 2007;132:2131-57.

5. Drucker DJ, Buse JB, Taylor K, Kendall DM, Trautmann M, Zhuang D, et al. Exenatide once weekly versus twice daily for the treatment of type 2 diabetes: a randomised, openlabel, non-inferiority study. Lancet 2008;372:1240-50.

6. Buse JB, Rosenstock J, Sesti G, Schmidt WE, Montanya E, Brett JH, et al. Liraglutide once a day versus exenatide twice a day for type 2 diabetes: a 26-week randomised, parallelgroup, multinational, open-label trial (LEAD-6). Lancet 2009;374:39-47.

7. Villanueva-Peñacarrillo ML, Puente J, Redondo A, Clemente F, Valverde I. Effect of GLP-1 treatment on GLUT2 and GLUT4 expression in type 1 and type 2 rat diabetic models. Endocrine 2001;15:241-8.

8. Holst JJ, Orskov C, Nielsen OV, Schwartz TW. Truncated glucagon-like peptide I, an insulin-releasing hormone from the distal gut. FEBS Lett 1987;211:169-74.

9. Tian L, Gao J, Hao J, Zhang Y, Yi H, O'Brien TD, et al. Reversal of new-onset diabetes through modulating inflammation and stimulating beta-cell replication in nonobese diabetic mice by a dipeptidyl peptidase IV inhibitor. Endocrinology 2010;151:3049-60.

10. Sano H, Terasaki J, Mishiba Y, Imagawa A, Hanafusa T. Exendin-4, a glucagon-like peptide-1 receptor agonist, suppresses pancreatic $\beta$-cell destruction induced by encephalomyocarditis virus. Biochem Biophys Res Commun 2011;404:756-61.

11. Li L, El-Kholy W, Rhodes CJ, Brubaker PL. Glucagonlike peptide-1 protects beta cells from cytokineinduced apoptosis and necrosis: role of protein kinase B. Diabetologia 2005;48:1339-49.

12. Lee YS, Jun HS. Anti-diabetic actions of glucagon-like peptide-1 on pancreatic beta-cells. Metabolism 2014;63:919.
13. Holst JJ, Knop FK, Vilsbøll T, Krarup T, Madsbad S. Loss of incretin effect is a specific, important, and early characteristic of type 2 diabetes. Diabetes Care 2011;34 Suppl 2:S251-7.

14. Holst JJ, Gromada J. Role of incretin hormones in the regulation of insulin secretion in diabetic and nondiabetic humans. Am J Physiol Endocrinol Metab 2004;287:E199206.

15. Hui H, Zhao X, Perfetti R. Structure and function studies of glucagon-like peptide-1 (GLP-1): the designing of a novel pharmacological agent for the treatment of diabetes. Diabetes Metab Res Rev 2005;21:313-31.

16. Suzuki S, Kawai K, Ohashi S, Mukai H, Yamashita K. Comparison of the effects of various C-terminal and $\mathrm{N}$-terminal fragment peptides of glucagon-like peptide-1 on insulin and glucagon release from the isolated perfused rat pancreas. Endocrinology 1989;125:3109-14.

17. Orskov C, Rabenhøj L, Wettergren A, Kofod H, Holst JJ. Tissue and plasma concentrations of amidated and glycineextended glucagon-like peptide I in humans. Diabetes 1994;43:535-9.

18. Gupta V. Glucagon-like peptide-1 analogues: an overview. Indian J Endocrinol Metab 2013;17:413-21.

19. Neumann JM, Couvineau A, Murail S, Lacapère JJ, Jamin $\mathrm{N}$, Laburthe M. Class-B GPCR activation: is ligand helixcapping the key? Trends Biochem Sci 2008;33:314-9.

20. Widmann C, Dolci W, Thorens B. Agonist-induced internalization and recycling of the glucagon-like peptide-1 receptor in transfected fibroblasts and in insulinomas. Biochem J 1995;310 ( Pt 1):203-14.

21. Runge S, Wulff BS, Madsen K, Bräuner-Osborne H, Knudsen LB. Different domains of the glucagon and glucagon-like peptide- 1 receptors provide the critical determinants of ligand selectivity. Br J Pharmacol 2003;138:787-94.

22. Wilmen A, Van Eyll B, Göke B, Göke R. Five out of six tryptophan residues in the $\mathrm{N}$-terminal extracellular domain of the rat GLP-1 receptor are essential for its ability to bind GLP-1. Peptides 1997;18:301-5.

23. López de Maturana R, Donnelly D. The glucagon-like peptide-1 receptor binding site for the N-terminus of GLP1 requires polarity at Asp198 rather than negative charge. FEBS Lett 2002;530:244-8.

24. Thorens B, Porret A, Bühler L, Deng SP, Morel P, Widmann C. Cloning and functional expression of the human islet GLP-1 receptor. Demonstration that exendin-4 is an agonist and exendin-(9-39) an antagonist of the receptor. Diabetes 1993;42:1678-82.

25. Wilmen A, Göke B, Göke R. The isolated N-terminal extracellular domain of the glucagon-like peptide-1 (GLP)-1 receptor has intrinsic binding activity. FEBS Lett 1996;398:43-7.

26. López de Maturana R, Treece-Birch J, Abidi F, Findlay JB, Donnelly D. Met-204 and Tyr-205 are together important for binding GLP-1 receptor agonists but not 
their N-terminally truncated analogues. Protein Pept Lett 2004;11:15-22.

27. Al-Sabah S, Donnelly D. The positive charge at Lys-288 of the glucagon-like peptide-1 (GLP-1) receptor is important for binding the N-terminus of peptide agonists. FEBS Lett 2003;553:342-6.

28. Beinborn M, Worrall CI, McBride EW, Kopin AS. A human glucagon-like peptide-1 receptor polymorphism results in reduced agonist responsiveness. Regul Pept 2005;130:1-6.

29. Garber AJ. Long-acting glucagon-like peptide 1 receptor agonists: a review of their efficacy and tolerability. Diabetes Care 2011;34 Suppl 2:S279-84.

30. Nauck MA, Kleine N, Orskov C, Holst JJ, Willms B, Creutzfeldt W. Normalization of fasting hyperglycaemia by exogenous glucagon-like peptide 1 (7-36 amide) in type 2 (non-insulin-dependent) diabetic patients. Diabetologia 1993;36:741-4.

31. Farilla L, Hui H, Bertolotto C, Kang E, Bulotta A, Di Mario U, et al. Glucagon-like peptide-1 promotes islet cell growth and inhibits apoptosis in Zucker diabetic rats. Endocrinology 2002;143:4397-408.

32. Imeryüz N, Yeğen BC, Bozkurt A, Coşkun T, VillanuevaPeñacarrillo ML, Ulusoy NB. Glucagon-like peptide-1 inhibits gastric emptying via vagal afferent-mediated central mechanisms. Am J Physiol 1997;273(4 Pt 1):G920-7.

33. Wettergren A, Wøjdemann M, Holst JJ. Glucagon-like peptide- 1 inhibits gastropancreatic function by inhibiting central parasympathetic outflow. Am J Physiol 1998;275(5 Pt 1):G984-92.

34. Ruan HB, Dietrich MO, Liu ZW, Zimmer MR, Li MD, Singh JP, et al. O-GlcNAc transferase enables AgRP neurons to suppress browning of white fat. Cell 2014;159:306-17.

35. Amato A, Cinci L, Rotondo A, Serio R, Faussone-Pellegrini MS, Vannucchi MG, et al. Peripheral motor action of glucagon-like peptide-1 through enteric neuronal receptors. Neurogastroenterol Motil 2010;22:664-e203.

36. Wettergren A, Wøjdemann M, Meisner S, Stadil F, Holst JJ. The inhibitory effect of glucagon-like peptide-1 (GLP-1) 7-36 amide on gastric acid secretion in humans depends on an intact vagal innervation. Gut 1997;40:597-601.

37. Gülpinar MA, Bozkurt A, Coşkun T, Ulusoy NB, Yegen BC. Glucagon-like peptide (GLP-1) is involved in the central modulation of fecal output in rats. Am J Physiol Gastrointest Liver Physiol 2000;278:G924-9.

38. Ayachi SE, Borie F, Magous R, Sasaki K, le Nguyen D, Bali JP, et al. Contraction induced by glicentin on smooth muscle cells from the human colon is abolished by exendin (9-39). Neurogastroenterol Motil 2005; 17:302-9.

39. Nakade Y, Tsukamoto K, Iwa M, Pappas TN, Takahashi T. Glucagon like peptide-1 accelerates colonic transit via central CRF and peripheral vagal pathways in conscious rats. Auton Neurosci 2007;131:50-6.

40. Law NM, Bharucha AE, Undale AS, Zinsmeister AR. Cholinergic stimulation enhances colonic motor activity, transit, and sensation in humans. Am J Physiol Gastrointest
Liver Physiol 2001;281:G1228-37.

41. Zhao S, Kanoski SE, Yan J, Grill HJ, Hayes MR. Hindbrain leptin and glucagon-like-peptide- 1 receptor signaling interact to suppress food intake in an additive manner. Int J Obes (Lond) 2012;36:1522-8.

42. Hayes MR, Skibicka KP, Leichner TM, Guarnieri DJ, DiLeone RJ, Bence KK, et al. Endogenous leptin signaling in the caudal nucleus tractus solitarius and area postrema is required for energy balance regulation. Cell Metab 2010;11:77-83.

43. Larsen PJ, Tang-Christensen M, Holst JJ, Orskov C. Distribution of glucagon-like peptide-1 and other preproglucagon-derived peptides in the rat hypothalamus and brainstem. Neuroscience 1997;77:257-70.

44. Baggio LL, Drucker DJ. Glucagon-like peptide-1 receptors in the brain: controlling food intake and body weight. J Clin Invest 2014; 124:4223-6.

45. Sisley S, Gutierrez-Aguilar R, Scott M, D'Alessio DA, Sandoval DA, Seeley RJ. Neuronal GLP1R mediates liraglutide's anorectic but not glucose-lowering effect. J Clin Invest 2014;124:2456-63.

46. Secher A, Jelsing J, Baquero AF, Hecksher-Sørensen J, Cowley MA, Dalbøge LS, et al. The arcuate nucleus mediates GLP-1 receptor agonist liraglutide-dependent weight loss. J Clin Invest 2014;124:4473-88.

47. Morton GJ, Schwartz MW. The NPY/AgRP neuron and energy homeostasis. Int J Obes Relat Metab Disord 2001;25 Suppl 5:S56-62.

48. Sapru HN. Role of the hypothalamic arcuate nucleus in cardiovascular regulation. Auton Neurosci 2013;175:38-50.

49. Doyle ME, Egan JM. Mechanisms of action of glucagon-like peptide 1 in the pancreas. Pharmacol Ther 2007;113:54693.

50. Holst JJ. The physiology of glucagon-like peptide 1. Physiol Rev 2007;87:1409-39.

51. Renström E, Eliasson L, Rorsman P. Protein kinase A-dependent and -independent stimulation of exocytosis by cAMP in mouse pancreatic B-cells. J Physiol 1997;502(Pt 1):105-18.

52. Shibasaki T, Takahashi H, Miki T, Sunaga Y, Matsumura K, Yamanaka M, et al. Essential role of Epac2/Rap1 signaling in regulation of insulin granule dynamics by cAMP. Proc Natl Acad Sci U S A 2007;104:19333-8.

53. Wang Y, Egan JM, Raygada M, Nadiv O, Roth J, MontroseRafizadeh C. Glucagon-like peptide-1 affects gene transcription and messenger ribonucleic acid stability of components of the insulin secretory system in RIN 104638 cells. Endocrinology 1995; 136:4910-7.

54. Vilsbøll T. The effects of glucagon-like peptide-1 on the beta cell. Diabetes Obes Metab 2009;11 Suppl 3:11-8.

55. Dunning BE, Foley JE, Ahrén B. Alpha cell function in health and disease: influence of glucagon-like peptide-1. Diabetologia 2005;48:1700-13.

56. Zander M, Madsbad S, Madsen JL, Holst JJ. Effect of 6-week course of glucagon-like peptide 1 on glycaemic control, 
insulin sensitivity, and beta-cell function in type 2 diabetes: a parallel-group study. Lancet 2002;359:824-30.

57. Lockie SH, Heppner KM, Chaudhary N, Chabenne JR, Morgan DA, Veyrat-Durebex C, et al. Direct control of brown adipose tissue thermogenesis by central nervous system glucagon-like peptide-1 receptor signaling. Diabetes 2012;61:2753-62.

58. López M, Diéguez C, Nogueiras R. Hypothalamic GLP-1: the control of BAT thermogenesis and browning of white fat. Adipocyte 2015;4:141-5.

59. Shimizu I, Hirota M, Ohboshi C, Shima K. Identification and localization of glucagon-like peptide- 1 and its receptor in rat brain. Endocrinology 1987;121:1076-82.

60. Cano G, Passerin AM, Schiltz JC, Card JP, Morrison SF, Sved AF. Anatomical substrates for the central control of sympathetic outflow to interscapular adipose tissue during cold exposure. J Comp Neurol 2003;460:303-26.

61. Uno T, Shibata M. Role of inferior olive and thoracic IML neurons in nonshivering thermogenesis in rats. Am J Physiol Regul Integr Comp Physiol 2001;280:R536-46.

62. Kim KW, Zhao L, Donato J Jr, Kohno D, Xu Y, Elias CF, et al. Steroidogenic factor 1 directs programs regulating dietinduced thermogenesis and leptin action in the ventral medial hypothalamic nucleus. Proc Natl Acad Sci U S A 2011;108:10673-8.

63. Jo YH. Endogenous BDNF regulates inhibitory synaptic transmission in the ventromedial nucleus of the hypothalamus. J Neurophysiol 2012;107:42-9.

64. López M, Varela L, Vázquez MJ, Rodríguez-Cuenca S, González CR, Velagapudi VR, et al. Hypothalamic AMPK and fatty acid metabolism mediate thyroid regulation of energy balance. Nat Med 2010;16:1001-8.

65. Martínez de Morentin PB, González-García I, Martins L, Lage R, Fernández-Mallo D, Martínez-Sánchez N, et al. Estradiol regulates brown adipose tissue thermogenesis via hypothalamic AMPK. Cell Metab 2014;20:41-53.

66. Ramadori G, Fujikawa T, Fukuda M, Anderson J, Morgan DA, Mostoslavsky R, et al. SIRT1 deacetylase in POMC neurons is required for homeostatic defenses against dietinduced obesity. Cell Metab 2010;12:78-87.

67. Mentlein R, Gallwitz B, Schmidt WE. Dipeptidyl-peptidase IV hydrolyses gastric inhibitory polypeptide, glucagon-like peptide-1(7-36)amide, peptide histidine methionine and is responsible for their degradation in human serum. Eur J Biochem 1993;214:829-35.

68. Plamboeck A, Holst JJ, Carr RD, Deacon CF. Neutral endopeptidase 24.11 and dipeptidyl peptidase IV are both mediators of the degradation of glucagon-like peptide 1 in the anaesthetised pig. Diabetologia 2005;48:1882-90.

69. Mentlein R. Dipeptidyl-peptidase IV (CD26): role in the inactivation of regulatory peptides. Regul Pept 1999;85:924.

70. Hansen L, Deacon CF, Orskov C, Holst JJ. Glucagon-like peptide-1-(7-36)amide is transformed to glucagon-like peptide-1-(9-36)amide by dipeptidyl peptidase IV in the capillaries supplying the L cells of the porcine intestine. Endocrinology 1999;140:5356-63.

71. Gee NS, Bowes MA, Buck P, Kenny AJ. An immunoradiometric assay for endopeptidase-24.11 shows it to be a widely distributed enzyme in pig tissues. Biochem J 1985;228:119-26.

72. Eng J, Kleinman WA, Singh L, Singh G, Raufman JP. Isolation and characterization of exendin-4, an exendin-3 analogue, from Heloderma suspectum venom. Further evidence for an exendin receptor on dispersed acini from guinea pig pancreas. J Biol Chem 1992;267:7402-5.

73. Kim W, Egan JM. The role of incretins in glucose homeostasis and diabetes treatment. Pharmacol Rev 2008;60:470512 .

74. Kolterman OG, Kim DD, Shen L, Ruggles JA, Nielsen LL, Fineman MS, et al. Pharmacokinetics, pharmacodynamics, and safety of exenatide in patients with type 2 diabetes mellitus. Am J Health Syst Pharm 2005;62:173-81.

75. Egan JM, Clocquet AR, Elahi D. The insulinotropic effect of acute exendin-4 administered to humans: comparison of nondiabetic state to type 2 diabetes. J Clin Endocrinol Metab 2002;87:1282-90.

76. Kolterman OG, Buse JB, Fineman MS, Gaines E, Heintz $\mathrm{S}$, Bicsak TA, et al. Synthetic exendin-4 (exenatide) significantly reduces postprandial and fasting plasma glucose in subjects with type 2 diabetes. J Clin Endocrinol Metab 2003;88:3082-9.

77. DeFronzo RA, Ratner RE, Han J, Kim DD, Fineman MS, Baron AD. Effects of exenatide (exendin-4) on glycemic control and weight over 30 weeks in metformin-treated patients with type 2 diabetes. Diabetes Care 2005;28:1092100.

78. DeFronzo RA, Okerson T, Viswanathan P, Guan X, Holcombe JH, MacConell L. Effects of exenatide versus sitagliptin on postprandial glucose, insulin and glucagon secretion, gastric emptying, and caloric intake: a randomized, cross-over study. Curr Med Res Opin 2008;24:2943-52.

79. Buse JB, Nauck M, Forst T, Sheu WH, Shenouda SK, Heilmann CR, et al. Exenatide once weekly versus liraglutide once daily in patients with type 2 diabetes (DURATION-6): a randomised, open-label study. Lancet 2013;381:117-24.

80. Diamant M, Van Gaal L, Stranks S, Northrup J, Cao D, Taylor K, et al. Once weekly exenatide compared with insulin glargine titrated to target in patients with type 2 diabetes (DURATION-3): an open-label randomised trial. Lancet 2010;375:2234-43.

81. Drucker DJ. Enhancing incretin action for the treatment of type 2 diabetes. Diabetes Care 2003;26:2929-40.

82. Mentis N, Vardarli I, Köthe LD, Holst JJ, Deacon CF, Theodorakis M, et al. GIP does not potentiate the antidiabetic effects of GLP-1 in hyperglycemic patients with type 2 diabetes. Diabetes 2011;60:1270-6.

83. Dharmalingam M, Sriram U, Baruah MP. Liraglutide: A 
review of its therapeutic use as a once daily GLP-1 analog for the management of type 2 diabetes mellitus. Indian J Endocrinol Metab 2011;15:9-17.

84. Chang AM, Jakobsen G, Sturis J, Smith MJ, Bloem CJ, An B, et al. The GLP-1 derivative NN2211 restores beta-cell sensitivity to glucose in type 2 diabetic patients after a single dose. Diabetes 2003;52:1786-91.

85. Russell-Jones D, Vaag A, Schmitz O, Sethi BK, Lalic N, Antic S, et al. Liraglutide vs insulin glargine and placebo in combination with metformin and sulfonylurea therapy in type 2 diabetes mellitus (LEAD-5 met+SU): a randomised controlled trial. Diabetologia 2009;52:2046-55.

86. Fala L. Tanzeum (Albiglutide): a once-weekly GLP-1 receptor agonist subcutaneous injection approved for the treatment of patients with type 2 diabetes. Am Health Drug Benefits 2015;8(Spec Feature):126-30.

87. Bush MA, Matthews JE, De Boever EH, Dobbins RL, Hodge RJ, Walker SE, et al. Safety, tolerability, pharmacodynamics and pharmacokinetics of albiglutide, a long-acting glucagon-like peptide-1 mimetic, in healthy subjects. Diabetes Obes Metab 2009;11:498-505.

88. Weissman PN, Carr MC, Ye J, Cirkel DT, Stewart M, Perry C, et al. HARMONY 4: randomised clinical trial comparing once-weekly albiglutide and insulin glargine in patients with type 2 diabetes inadequately controlled with metformin with or without sulfonylurea. Diabetologia 2014;57:2475-84

89. Pratley RE, Nauck MA, Barnett AH, Feinglos MN, Ovalle F, Harman-Boehm I, et al. Once-weekly albiglutide versus once-daily liraglutide in patients with type 2 diabetes inadequately controlled on oral drugs (HARMONY 7): a randomised, open-label, multicentre, non-inferiority phase 3 study. Lancet Diabetes Endocrinol 2014;2:289-97.

90. Woodward HN, Anderson SL. Once-weekly albiglutide in the management of type 2 diabetes: patient considerations. Patient Prefer Adherence 2014;8:789-803.

91. Barrington P, Chien JY, Showalter HD, Schneck K, Cui S, Tibaldi F, et al. A 5-week study of the pharmacokinetics and pharmacodynamics of LY2189265, a novel, long-acting glucagon-like peptide- 1 analogue, in patients with type 2 diabetes. Diabetes Obes Metab 2011;13:426-33.

92. Fala L. Trulicity (Dulaglutide): a new GLP-1 receptor agonist once-weekly subcutaneous injection approved for the treatment of patients with type 2 diabetes. Am Health Drug Benefits 2015;8(Spec Feature):131-4.

93. Wysham C, Blevins T, Arakaki R, Colon G, Garcia P, Atisso $\mathrm{C}$, et al. Erratum. efficacy and safety of dulaglutide added onto pioglitazone and metformin versus exenatide in type 2 diabetes in a randomized controlled trial (AWARD-1). Diabetes Care 2014;37:2159-67.

94. Giorgino F, Benroubi M, Sun JH, Zimmermann AG, Pechtner V. Efficacy and safety of once-weekly dulaglutide versus insulin glargine in patients with type 2 diabetes on metformin and glimepiride (AWARD-2). Diabetes Care 2015;38:2241-9.

95. Umpierrez G, Tofé Povedano S, Pérez Manghi F, Shurzinske L, Pechtner V. Efficacy and safety of dulaglutide monotherapy versus metformin in type 2 diabetes in a randomized controlled trial (AWARD-3). Diabetes Care 2014;37:2168-76.

96. Dungan KM, Povedano ST, Forst T, González JG, Atisso $\mathrm{C}$, Sealls W, et al. Once-weekly dulaglutide versus oncedaily liraglutide in metformin-treated patients with type 2 diabetes (AWARD-6): a randomised, open-label, phase 3, non-inferiority trial. Lancet 2014;384:1349-57.

97. Kothare PA, Linnebjerg H, Isaka Y, Uenaka K, Yamamura A, Yeo KP, et al. Pharmacokinetics, pharmacodynamics, tolerability, and safety of exenatide in Japanese patients with type 2 diabetes mellitus. J Clin Pharmacol 2008;48:1389-99.

98. St Onge EL, Miller SA. Albiglutide: a new GLP-1 analog for the treatment of type 2 diabetes. Expert Opin Biol Ther 2010;10:801-6

99. Smith LL, Mosley JF 2nd, Parke C, Brown J, Barris LS, Phan LD. Dulaglutide (Trulicity): The Third Once-Weekly GLP1 Agonist. P T 2016;41:357-60. 